\title{
SOME PHYSICAL PROPERTIES OF AI-Sn-Zn MELTS.
}

\author{
V. Sidorov ${ }^{1}$, J. Drápala ${ }^{2}$, S. Uporov ${ }^{1}$, A. Sabirzyanov ${ }^{1}$, P. Popel $^{1}$, \\ A. Kurochkin ${ }^{1}$ and K. Grushevskij ${ }^{1}$ \\ ${ }^{1}$ Ural State Pedagogical University, 620017 Ekaterinburg, Russia, fominans@,rambler.ru \\ ${ }^{2}$ Institute of Metallurgy UB RAS, 620016 Ekaterinburg, Russia
}

\begin{abstract}
Al-Sn-Zn alloys are considered to be a good alternative for lead-containing solders; however, their physical properties at high temperatures are investigated insufficiently. In this work we have studied density (by gamma-absorption method), electrical resistivity (by contactless method in rotating magnetic field) and magnetic susceptibility (by Faraday's method) of some Al-Sn-Zn alloys containing up to $10 \%$ of aluminum and up to $65 \%$ of zinc. The enlargement of zinc content resulted in the decrease in density and susceptibility values, except for one sample. The resistivity values practically didn't depend on zinc content in crystalline state, whereas it had maximum for one of the samples in liquid state, which might be attributed to the appearance of ternary high-melted intermetallic compound. The hysteresis, i.e. incoincidence of heating and cooling curves in electronic properties, which has been observed for tin-rich samples, might be due to irreversible transition from microheterogeneous state of the melt to true solution state. The work has been made in the frames of COST Action MP0602.
\end{abstract}

\section{Introduction}

Until recently the lead-tin alloy of eutectic composition has been generally used as a solder for electric circuits. But during the last decade the ecological demands became much stronger. Because of the toxicity of lead for health and environment, the search for new lead-free soldering materials and the replacement of leadcontaining solders with them are in progress [1,2]. Two international actions, one after another, served to unite efforts of researchers and manufacturers. They were COST Actions 531 and MP0602, financed by EC.

It is difficult to find an alternative to the traditional lead-tin solders, because the solder is bound to match many requirements, such as optimal melting temperature, high durability of soldered joints, good wetting of joining surfaces and low cost price. With regard to all characteristics a perfect alternative to the traditional solders has not been found yet [3].

$\mathrm{Al}-\mathrm{Sn}-\mathrm{Zn}$ alloys are very promising as soldering materials of new generation. They have low melting temperature and rather high mechanical properties. For example, Fujitsu Corporation reported of successful use of $\mathrm{Al}-\mathrm{Sn}-\mathrm{Zn}$ compositions in commercial purposes, starting in $2002[4,5]$. The authors pointed out the high corrosion resistance of these alloys ascribed to the presence of aluminum. In [6] the working properties of this alloys have been studied in comparison with $\mathrm{Sn}-\mathrm{In}$, $\mathrm{Sn}-\mathrm{Bi}, \mathrm{Sn}-\mathrm{Ag}-\mathrm{Cu}$ и $\mathrm{Sn}-\mathrm{Bi}-\mathrm{Ag}$ and the conclusion has been made that $\mathrm{Al}-\mathrm{Sn}-\mathrm{Zn}$ is a candidate for the role of a main lead-free solder. Due to the interest of manufacturers its properties have been actively studied in recent years. In [7] the data of crystallization temperature range and equilibrium phases formed in the soldered joint zone are given.

It is well-known that the state of a melt before crystallization has noticeable effect on structure and properties of solidified material. And yet physical properties of $\mathrm{Al}-\mathrm{Sn}-\mathrm{Zn}$ system at high temperatures, especially in liquid state, are studied insufficiently. That is why in the present work we have investigated density, electrical resistivity and magnetic susceptibility of some $\mathrm{Al}-\mathrm{Sn}-\mathrm{Zn}$ alloys, containing up to $10 \%$ of aluminum and up to $65 \%$ of zinc, in wide temperature range.

\section{Experiment}

1. Density was measured by absolute variant of gammaabsorption method. It is based on the known law of attenuation of gamma-rays:

$$
I=B \cdot I_{0} \cdot \exp (-\mu \cdot l \cdot d)
$$

where $I$ and $I_{0}$ are beam intensities before and after the specimen, respectively; $l$ is the path length of gammaquants in the specimen; $\mu$ is the mass attenuation coefficient depending on the chemical composition of the alloy and the energy $W$ of gamma-quants; $B$ is the accumulation factor depending on the setup geometry and $W ; d$ is density of the material. 
By measuring $I, I_{0}, l$ and calculating $B$ one can determine the specimen density using the known value of $\mu:$

$$
d=\frac{\ln \left(I_{0} / I\right)+\ln B}{\mu \cdot l}
$$

The main difficulty in absolute variant of this method is the necessity of involving the reference values of mass attenuation coefficient $\mu$. Unfortunately, the accuracy of available data on $\mu$ is rather low. But an analysis of literature data performed in [8] shows that when the ${ }^{137} \mathrm{Cs}$ source is employed with gamma-quant energy $\mathrm{W}=0.66 \mathrm{MeV}$, the $\mu$ values for relevant elements can be calculated with an accuracy of $0.4 \%$. Thus the uncertainty in density absolute values definition in our experiments was at a level of $0.4-0.5 \%$ depending on the composition.

2. Electrical resistivity of samples was determined by contactless method in rotating magnetic field. The $\rho$ values were obtained from the angle of twist $\varphi$ of the specimen suspended on the elastic thread under the influence of the rotating magnetic field:

$$
\rho=K \cdot i^{2} \cdot h \cdot R^{4} / \varphi
$$

where $i$ is the current generating the rotating magnetic field; $K$ is the instrumental constant; $h$ and $R$ are height and radius of the sample of cylindrical form. To minimize the systematic error in $\rho$ definition, the samples having $\mathrm{h} / \mathrm{R}=1,82 \div 2,02$ were used [9]. The total uncertainty in resistivity values definition was $\pm 5 \%$.

3. Magnetic susceptibility was determined by Faraday's method that is based on the measurement of the force acting upon the specimen placed in non-uniform magnetic field. On account of difficulties related with the accurate fixation of the specimen position and the use of polepieces of special shape, the relative variant of the method was employed, in which a comparison is made of the $F_{z}$ and $F_{z 0}$ values obtained in experiments with the investigated sample and the standard specimen with the known magnetic susceptibility, respectively. Then we have:

$$
\chi=\chi_{0} \cdot \frac{m_{0}}{m} \cdot \frac{F_{z}}{F_{z 0}}
$$

where $m$ and $m_{0}$ are the masses of the specimen and the standard, respectively.

Because the investigated alloys were very low magnetic materials, the susceptibility absolute values were determined with the accuracy at a level of $\pm 10 \%$.
All the experiments were performed during heating and the subsequent cooling with the steps of 5-20 and isothermal expositions for 5-20 $\mathrm{min}$ at each temperature. The chambers were preliminary outgased up to $10^{-2} \mathrm{~Pa}$ and then filled in with helium of high purity up to $1.1 \cdot 10^{5}$ $\mathrm{Pa}$. The experiments were performed either in $\mathrm{BeO}$ or in $\mathrm{Al}_{2} \mathrm{O}_{3}$ crucibles.

The samples compositions together with liquidus temperatures, determined by DTA, are given in table 1 .

Table 1. The compositions and liquidus temperatures of the samples

\begin{tabular}{|c|l|c|}
\hline № & \multicolumn{1}{|c|}{ Composition } & $\mathrm{T}_{1}$ (DTA) ${ }^{0} \mathrm{C}$ \\
\hline 1 & $\mathrm{Zn}-91$ at.\% $\mathrm{Sn}-2.5$ at.\% $\mathrm{Al}$ & 272 \\
\hline 2 & $\mathrm{Zn}-80$ at.\% $\mathrm{Sn}-8$ at.\% $\mathrm{Al}$ & 388 \\
\hline 3 & $\mathrm{Zn}-70.5$ at.\% $\mathrm{Sn}-4.7$ at.\% $\mathrm{Al}$ & 329 \\
\hline 4 & $\mathrm{Zn}-50$ at.\% $\mathrm{Sn}-7$ at.\% $\mathrm{Al}$ & 335 \\
\hline 5 & $\mathrm{Zn}-25$ at.\% $\mathrm{Sn}-10$ at.\% $\mathrm{Al}$ & 340 \\
\hline
\end{tabular}

\section{Results \& discussion}

The results of density, electrical resistivity and magnetic susceptibility measurements of Al-Sn-Zn alloys are given in Fig. 1-3.

1. Density. The temperature dependencies were linear for all samples in liquid state. The curves obtained in the course of heating and subsequent cooling coincided with each other within the limits of experimental error. The experimental curves were fitted with linear function $d=d_{L}\left[1-\alpha\left(t-t_{L}\right)\right]$, where $d_{L}$ is density at liquidus temperature; $\alpha$ is temperature expansion coefficient. Liquidus temperatures $t_{L}$ were taken from DTA results.

2. Electrical resistivity. The temperature dependencies were linear for all samples and were fitted with linear function $\rho=\rho_{L}\left[1+\beta\left(t-t_{L}\right)\right]$, where $\rho_{L}$ is the resistance at liquidus, $\beta$ is temperature resistivity coefficient. The temperature dependencies were linear and fitted with linear function in solid state, too. Resistance appeared constant vs temperature for the samples 4 and 5 in liquid state. The sample 4 had the highest resistivity of all samples, in solid and especially in liquid state. The heating and cooling curves coincided with each other in liquid state. But they didn't quite coincide with each other in solid state for samples 1 and 2, or one may say there is a hysteresis between them. That is an evidence that irreversible transition took place in the melt after it had been heated up to $500{ }^{\circ} \mathrm{C}$. 

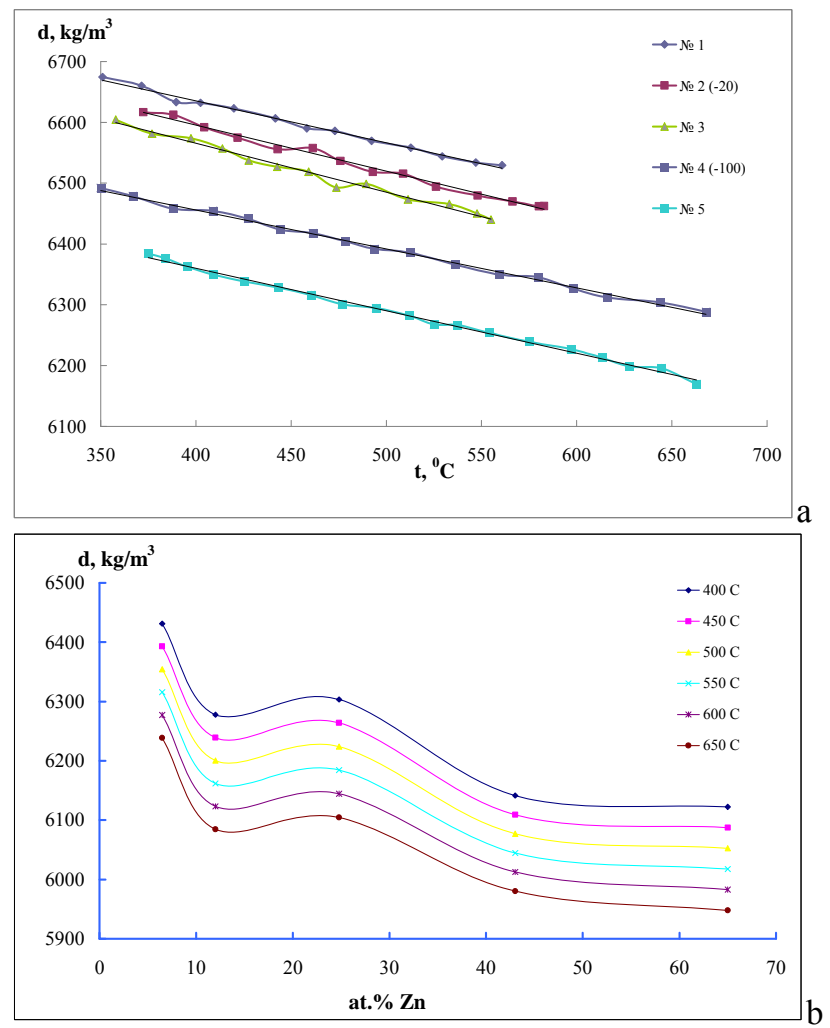

Fig.1. Density vs temperature and concentration curves of some Al-Sn-Zn melts. a) Temperature dependence; b) Concentration dependence
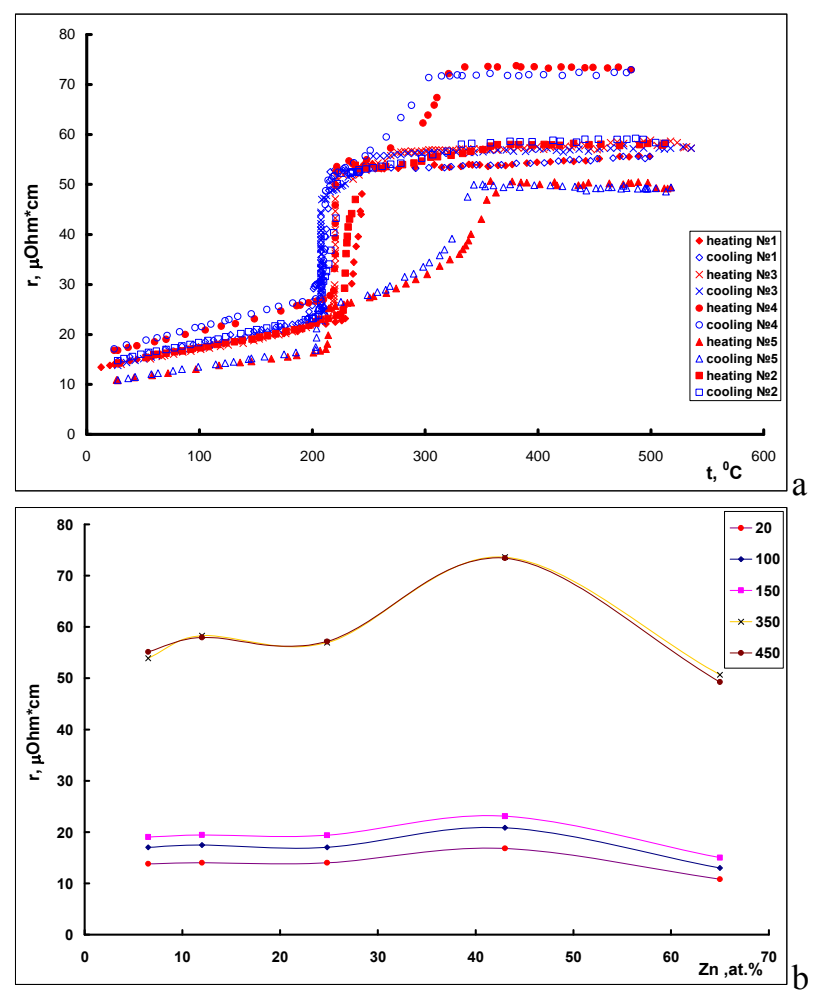

Fig.2. Resistivity vs temperature and concentration curves of some Al-Sn-Zn melts a) Temperature dependence; b) Concentration dependence

3. Magnetic susceptibility. For all the samples $\chi$ was positive below $\mathrm{T}=200-210{ }^{\circ} \mathrm{C}$ (probably solidus), and became negative above this temperature (for sample $5 \chi$ became negative above $140{ }^{\circ} \mathrm{C}$, but the jump down was fixed at $210{ }^{\circ} \mathrm{C}$ as well). No anomalies at liquidus temperatures were fixed. One can see the hysteresis or the incoincidence of heating and cooling curves for samples 1 and 2 in solid state. That occured after the heating up to $500{ }^{\circ} \mathrm{C}$ and might be the evidence of irreversible transition in the melt.
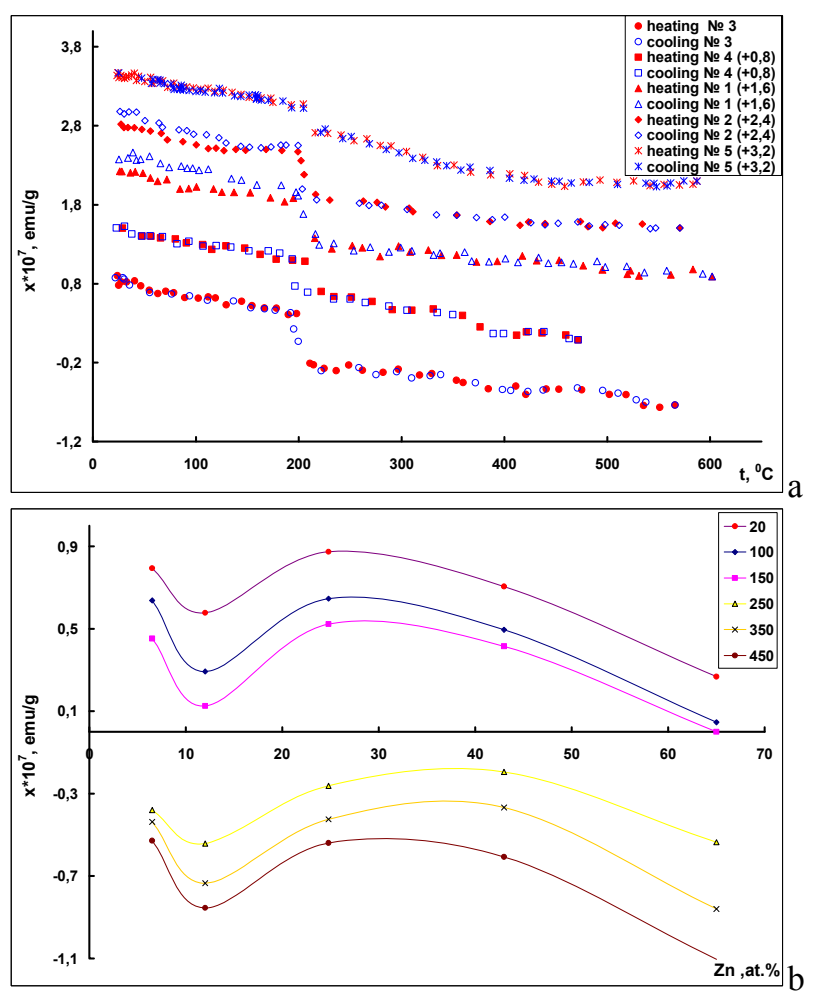

Fig.3. Magnetic susceptibility of some Al-Sn-Zn melts a) Temperature dependence; b) Concentration dependence

Analyzing density and susceptibility data one can see that the enlargement of zinc content provides the decrease in these properties values. It is rather understandable because zinc is the most light weight element in this composition and is diamagnetic both in solid and liquid states. However, the composition 2 does not correspond to this trend and this is necessary to take into account while creating new solders.

As for resistivity data, the property value practically didn't depend on zinc content in crystalline state, whereas it had maximum for sample 4 in liquid state. This fact can be attributed to the appearance of ternary high-melted intermetallic compound.

Let us mention the hysteresis on resistivity and susceptibility fixed for samples 1 and 2 . This two compositions are near-eutectic ones and the existence of hysteresis proves our idea [10] that eutectic compositions differ significantly from hypo- and hyper-eutectic alloys in properties sensitive to electronic structure. Hence, it becomes possible to vary to some extent physical properties of such compositions using different heat treatment of the melt before crystallization. 


\section{Conclusions}

The composition $1(91 \% \mathrm{Sn}-6.5 \% \mathrm{Zn}-2.5 \% \mathrm{Al})$ has the least melting temperature. Judging from DTA results and the electrical resistance vs temperature dependency obtained in this work this composition relates to the eutectic point. As soon as the melting temperature plays the decisive role for the solder choice this composition may be good for replacement of lead-containing solders.

The composition $5(25 \% \mathrm{Sn}-65 \% \mathrm{Zn}-10 \% \mathrm{Al})$ attracts attention due to the low temperature expansion coefficient. That may be useful when temperature stability is important.

The hysteresis, i.e. incoincidence of heating and cooling curves in electronic properties, which has been observed for tin-rich samples, might be due to irreversible transition from microheterogeneous state of the melt to true solution state.

The work is supported by Federal Target Program of Russian Ministry of Education - FTP (NK-255P/1 and NK-16P/6) and RFBR (grant № 09-03-90450-Ukr). The work has been made in the frames of COST Action MP0602.

\section{References}

1. J. Chang-Bing Lee, Y-L. Yao, F-Y. Chiang, P.J. Zheng, C.C. Liao, Y.S. Chou. Characterization Study of Lead-free SnCu Plated Packages, Proc. IEEE Elect. Comp. \& Tech. Conf., 2002, P. 12381245.

2. W.J. Plumbridge. The Analysis of Creep Data for Solder Alloys, Soldering \& Surface Mount Technol. 15 (1), 2003, P.26-30.).

3. J. Zhao, Y. Mutoh, Y. Miyashita, L. Wang. Fatigue crack growth behavior of $\mathrm{Sn}-\mathrm{Pb}$ and $\mathrm{Sn}$-based leadfree solders. Engineering Fracture Mechanics, 2003, V. 70, P.2187-2197.

4. M. Kitajima, T. Shono. Development of $S n-Z n-A l$ lead-free solder alloys. Fujitsu Scientific and Technical Journal. Vol.41, Issue 2, 225-235.

5. H. Dan, Z. Jian, L.P. Pei. Corrosion performance of $\mathrm{Pb}$-free $\mathrm{Sn}-\mathrm{Zn}$ solders in salt spray. Proceedings of International Conference on Electronic Packaging Technology and High Density Packaging, ICEPTHDP 2008, Pudong, Shanghai; 2008, N 4607082.

6. P. Geng, R. Aspandiar, T. Byrne, F. Pon, D. Suh, A. McAllister, A. Nazario, P. Paulraj, N. Armendariz, T. Martin, T. Worley. Alternative lead-free solder joint integrity under room temperature mechanical load. In: Thermomechanical Phenomena in Electronic Systems - Proceedings of the Intersociety Conference, V.2, 2004, P.304-309.

7. D. Soares, C. Vilarinho, J. Barbosa, R. Silva, F. Castro. Effect of the Bi content on the interface reaction between copper substrate and $\mathrm{Sn}-\mathrm{Zn}-\mathrm{Al}-\mathrm{Bi}$ lead-free solder. Revista de Metallurgia (Madrid), V. SPEC, 2005, P.208-212.

8. P.S. Popel, V.A. Konovalov, A.V. Porotov. On the accuracy of absolute measurements of density with gamma-method. In: Gamma-method in metallurgical experiment. Novosibirsk, 1981. P. 55-64. (In Russian)

9. I. Brodova, P, Popel, G, Eskin. Liquid metal processing: application to Al alloys. Fransis and Tailor. 2000.

10. A. Sabirzyanov, V. Sidorov, D. Yagodin, S. Uporov, K. Grushevskii, K. Shunyaev. The physical properties of $\mathrm{Sn}-\mathrm{Bi}$ and $\mathrm{Sn}-\mathrm{Ag}$ melt melts near the eutectic compositions. Mathematical modeling and computer simulation of material technologies, Proc. of the 5 Int. Conf. 2008. P.1-167. 